http://doi.org/10.35784/iapgos.2383

\title{
MODELING ELECTROMAGNETIC NANOSTRUCTURES AND EXPERIMENTING WITH NANOELECTRIC ELEMENTS TO FORM PERIODIC STRUCTURES
}

\author{
Miloslav Steinbauer ${ }^{1}$, Roman Pernica ${ }^{1}$, Jiri Zukal ${ }^{1}$, Radim Kadlec $^{1}$, Tibor Bachorec ${ }^{1}$, Pavel Fiala ${ }^{2}$ \\ ${ }^{1}$ Brno University of Technology, Department of Theoretical and Experimental Electrical Engineering, Brno, Czech Republic \\ ${ }^{2}$ Brno University of Technology, SIX Research Center, Brno, Czech Republic
}

\begin{abstract}
We discuss the numerical modeling of electromagnetic, carbon-based periodic structures, including graphene, graphane, graphite, and graphyne. The materials are suitable for sub-micron sensors, electric lines, and other applications, such as those within biomedicine, photonics, nanoand optoelectronics; in addition to these domains and branches, the applicability extends into, for example, microscopic solutions for modern SMART elements. The proposed classic and hybrid numerical models are based on analyzing a periodic structure with a high repeatability, and they exploit the concept of a carbon structure having its fundamental dimension in nanometers. The models can simulate harmonic and transient processes; are capable of evaluating the actual random motion of an electric charge as a source of spurious signals; and consider the parameters of harmonic signal propagation along the structure. The results obtained from the analysis are utilizable for the design of sensing devices based on carbon periodic structures and were employed in experiments with a plasma generator. The aim is to provide a broader overview of specialized nanostructural modeling, or, more concretely, to outline a model utilizable in evaluating the propagation of a signal along a structure's surface.
\end{abstract}

Keywords: nanomaterial, graphene, graphite, experimental modeling, hydrogen bond, periodic structure

\section{MODELOWANIE NANOSTRUKTUR ELEKTROMAGNETYCZNYCH I EKSPERYMENTY Z ELEMENTAMI NANOELEKTRYCZNYMI W CELU TWORZENIA STRUKTUR OKRESOWYCH}

\begin{abstract}
Streszczenie. W artykule omówiony zostat proces numerycznego modelowania elektromagnetycznych, węglowych struktur okresowych, w tym grafenu, grafanu, grafitu i grafinu. Materiały te nadają się do czujników submikronowych, przewodów elektrycznych i innych zastosowań, takich jak biomedycyna, fotonika, nano- i optoelektronika. Oprócz tych dziedzin i gatęzi przemystu, zastosowanie materiałów pokrywa się także na przykład z mikroskopijnymi rozwiazaniami dla nowoczesnych elementów SMART. Proponowane klasyczne i hybrydowe modele numeryczne opieraja sie na analizie okresowej struktury o wysokiej powtarzalności $i$ wykorzystuja koncepcje struktury węglowej o podstawowym wymiarze w nanometrach. Modele moga symulowac procesy harmoniczne i przejściowe, potrafia ocenić rzeczywisty losowy ruch ładunku elektrycznego jako źródła fatszywych sygnałów $i$ uwzględniaja parametry propagacji sygnału harmonicznego wzdluż konstrukcji. Rezultaty uzyskane $w$ wyniku analizy można wykorzystać do projektowania czujników opartych na węglowych strukturach okresowych oraz do eksperymentów z generatorem plazmy. Celem jest zapewnienie szerszego przegladu specjalistycznego modelowania nanostrukturalnego lub, bardziej konkretnie, zarysu modelu nadajacego się do oceny propagacji sygnału wzdtuz powierzchni struktury.
\end{abstract}

Słowa kluczowe: nanomateriał, grafen, grafit, modelowanie eksperymentalne, wiązanie wodorowe, struktura okresowa

\section{Introduction}

The current decade has witnessed a major rise of interest in graphene [4, 5], Fig. 1, a carbon-based, single-layer periodic material. However, one-atom layered systems were investigated previously, with attempts made at estimating their mechanical and electrical properties via macroscopic experiments [24, 38] or theoretical considerations [40]. Graphene has been successfully manufactured from graphite, which essentially comprises periodically bonded carbon atoms arranged in multiple layers (Fig. 2). A further monolayered carbon periodic system, with bonds to hydrogen or other atomic nuclei, is commonly referred to as graphane (Fig. 3). Even though the polymer (with a benzene core or graphane base element) has not become a subject of mainstream research or found practical application to date, it shows significant potential for electronics and nanoelectronics. It has been identified through theoretical modeling as an advantageous material to facilitate the manufacturing of nanoelectric signal transmission lines [20]. Within the present investigation of single-atom carbon substances $[4,5,20,24,30$, $38,40,50]$, however, only few laboratories produce deterministic models of carbon-based nanomaterials. Another periodically structured form of carbon, graphyne (Fig. 4), exhibits interatomic bonding different from that of related carbon systems and can be shaped into pre-selected patterns or periodic motifs.

This paper compares several structural models of graphite, graphene, and graphane samples, focusing on an analysis and evaluation of the electromagnetic wave propagation along such systems. Earlier research and modeling [8, 12, 13, 16, 32, 46] point to the influence exerted by the actual oscillation of a periodically arranged carbon structure on a transmitted signal; such an impact is parametrically expressed as $\mathrm{S} / \mathrm{N}$. Moreover, in connection with the relevant numerical models, the question of how large a signal (electric current) can be smoothly carried along a nanoelectric line. Some authors consider graphene usable for logic or memory circuits in microelectronics [30, 44, 50]. In the above context, our study is intended to outline the possibilities of stochastic and deterministic methods [22, 23, 49] in numerical modeling and to examine the modeled sample periodic carbon structures in terms of the electromagnetic properties that may support the designing of a system to transmit a signal; the signal is describable by both the relevant electric power $P$ and its density expressed via the Poynting vector $\Pi$. We also refer to various options of characterizing other properties and parameters (such as the $\mathrm{S} / \mathrm{N}$ ratio) which appear to be indispensable in forming a nanoelectric element. The resulting information and data are utilizable especially in photonics, nanoelectronics, and associated subdomains of nanoelectronic system engineering. An interesting aspect lies in the analysis and evaluation of an electromagnetic wave and its propagation at the visible (in the order of hundreds of $100 \mathrm{THz}$ ), infrared (units to tens of $\mathrm{THz}$ ), or lower (units to hundreds of $\mathrm{GHz}$ ) spectral frequencies. The spectra are of particular interest for the given branch of engineering, as they offer broad application potential $[9,31,41]$. To set up the geometrical dimensions of the periodic system models at the atomic level and to design or analyze the structures in a stochastic model, we followed several relevant papers, including [26, 27, 45].

According to the research presented in $[8,12,13,16,20,22$, $23,32,44,46,49]$, the periodic structure of graphene exhibits certain interesting electrical and electromagnetic properties regarding the propagation of an electromagnetic wave. The referenced articles nevertheless do not provide a clear conclusion as to prospective application of periodic structures with exact 
properties in the field of EMG wave propagation; these structures can be based on either natural or artificial materials.

The concept of our study involved assembling several numerical models and performing their analyses to evaluate parameters such as the $\mathrm{S} / \mathrm{N}$ ratio of the actual structure carrying the useful signal and to determine the maximum current density that may load the system without destructive effects. Figure 5 displays some of the carbon-based periodic structures tested within the investigation outlined herein.

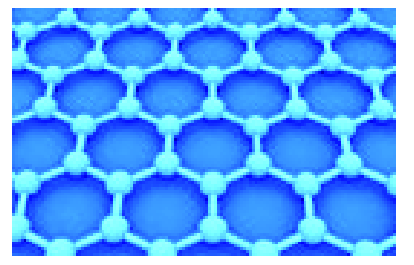

Fig. 1. Arrangement of carbon periodic structures: a graphene layer

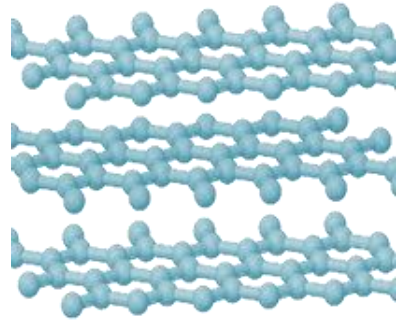

Fig. 2. Arrangement of carbon periodic structures: a graphite layer
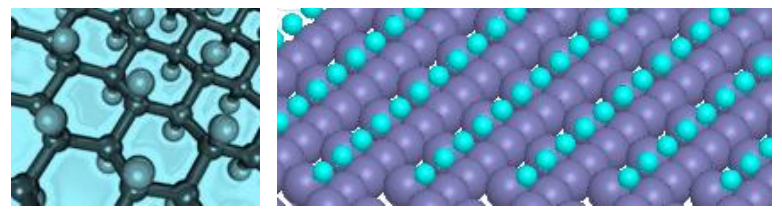

Fig. 3. Arrangement of carbon periodic structures: a layer of graphane, and its bonds to hydrogen

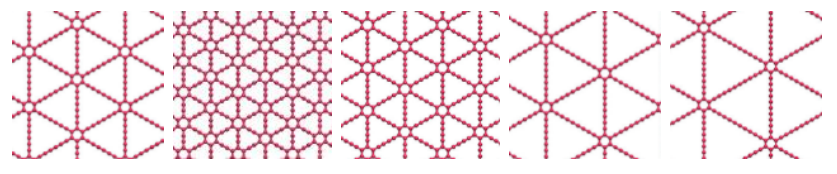

Fig. 4. Arrangement of carbon periodic structures: a graphyne layer at various levels

In evaluating these structures and their frequency responses to incident electromagnetic waves, it is necessary to employ convenient tools to facilitate a combined theoretical and experimental analysis. Such a process then has to be built on a specific geometrical and numerical model, and this model should respect the character of the probabilistic mathematical model; the uncertainty of the occurrence of an electric charge $q$; and the frequency of the transmitted signal $f_{\mathrm{t}}$ compared to the first harmonic frequency $f_{\mathrm{a} 1}[22,23,49]$, which is defined by the motion of the elementary charged parts of an atom with a diameter $d_{\mathrm{a} 1}$. We have:

$$
f_{t} \ll \frac{c}{d_{a 1}}
$$

where $c$ is the speed of light in vacuum, and $f_{\mathrm{a} 1}=c / d_{\mathrm{a} 1}$. The model embodies an application of the quantum-mechanical model of matter and the stochastic distribution of electric charges in individual elements of the structure. Although the structure is large, it exhibits a significant degree of periodicity; thus, it is possible to utilize, up to a certain level of complexity, the known finite methods (the finite and boundary element techniques or the finite volume method combined with a deterministic stochastic model). An example is provided in Fig. 5, via the design of a single conductor being a structure with a nonconductive space around each atom; more concretely, we can refer to Figs. 5d, 5e and the model of a coaxial, symmetric electric line comprising two polymer systems formed on a graphane basis.
In any such geometrical arrangement of a periodic nanostructure, it is suitable to analyze the EMG field at the level of structure elements with respect to the evaluation of known macroscopic quantities, including the surface power flux density and the electric and magnetic field intensities and specific fluxes for the harmonic behavior of signal propagation along the structure or for transient states of signal propagation along similar structures. As regards the proposed frequency-dependent EMG field analysis, the field comprises two basic domains: A) $f_{\mathrm{t}} \in\left\langle 1 \cdot 10^{6} ; 500 \cdot 10^{9}\right\rangle[\mathrm{Hz}], f_{\mathrm{a} 1} \approx 2 \cdot 10^{13}[\mathrm{~Hz}]$, which satisfies the above precondition (1), and B) $f_{\mathrm{t}} \in\left\langle 20 \cdot 10^{13} ; 40 \cdot 10^{13}\right\rangle[\mathrm{Hz}]$, $f_{\mathrm{a} 1} \approx 2 \cdot 10^{13} \quad[\mathrm{~Hz}]$, which does not satisfy precondition (1). In the former domain, A), the numerical analysis is then carried out via the classic approach, simulating the propagation of an electromagnetic wave in a harmonic model formulated by using reduced Maxwell's equations, [1, 34, 39, 43, 48]; in the latter region, B), the hybrid technique is employed to evaluate the propagation of an electromagnetic wave in a transient model formulated by means of reduced Maxwell's equations, [1, 20, 34, 39, 43, 48].

In model analyses where the electromagnetic field quantities are not evaluated at comparable magnitudes and sizes of the wavelength and the geometric structure $[30,31,32,33,34,35,36$, $37,38,39,40,41,42,43,44,45]$, the mathematical model does not necessarily have to be formed with respect to the quality criterion. Thus, the most convenient approach is selected according to the type of analysis planned and the numerical model designed. If an analysis of signals on a nano- or microstructure is to be performed, we can set up the numerical model based on the condition (1) - ad A) $f_{\mathrm{t}} \in\left\langle 1 \cdot 10^{6} ; 500 \cdot 10^{9}\right\rangle[\mathrm{Hz}]$, $f_{\mathrm{a} 1} \approx 2 \cdot 10^{13}[\mathrm{~Hz}]$, facilitating:

1) evaluation of both the transient processes which capture the motion of the electrically charged objects (electrons) and the electromagnetic couplings known from physicochemical descriptions of inorganic and organic material structures [10, 20,23], and

2) harmonic analysis and evaluation of the $S$ and $Z$ parameters, with represented distribution of the electromagnetic field in the time and frequency domains $[6,10,17,19]$.
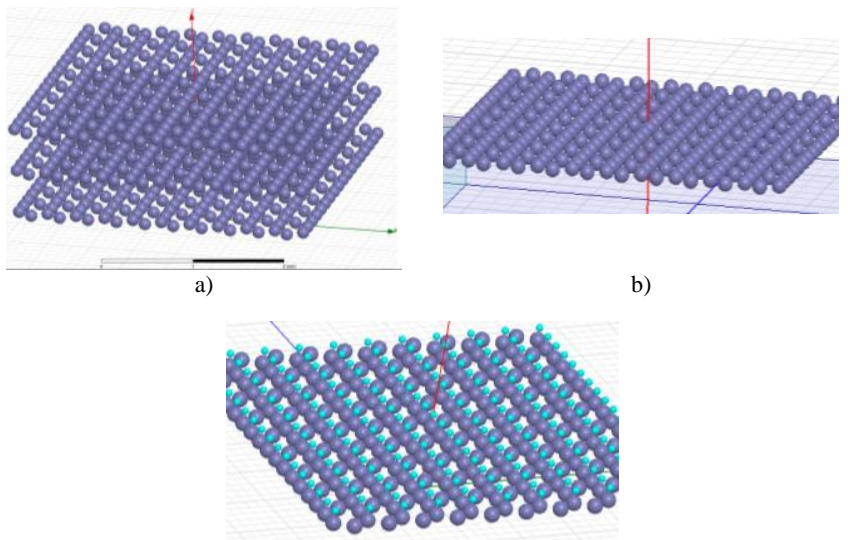

c)

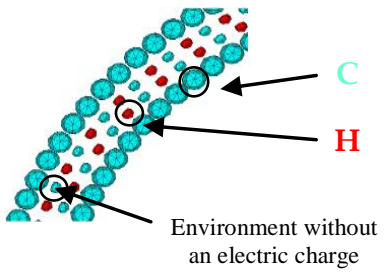

d)

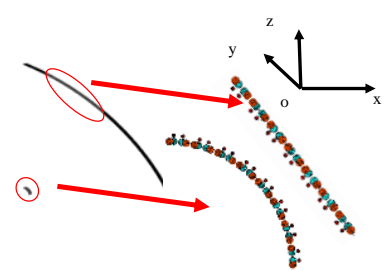

Fig. 5. Model of various geometrical structures of carbon nanomaterials: a) graphite; b) graphene; c) graphane; d) a graphane-based coaxial line model having the radius ratio of $1.4 ;$ e) a graphane-based coaxial line with the radius ratio of 30 
If the desired task is to analyze and evaluate the distribution of the electromagnetic field at the level of the nanostructure elements (nanometric objects; condition (1), ad B) $\left.f_{\mathrm{t}} \in\left\langle 20 \cdot 10^{13} ; 40 \cdot 10^{13}\right\rangle[\mathrm{Hz}], f_{\mathrm{a} 1} \approx 2 \cdot 10^{13}[\mathrm{~Hz}]\right)$, the model should include:

1) a harmonic analysis and evaluation of the $S$ parameters, with a swept frequency for the expected band, and

2) a different, ring theory-based design [22, 23, 49] to evaluate the electromagnetic field and to carry out an analysis with a swept frequency spectrum.

\section{A periodic structure (single layered)}
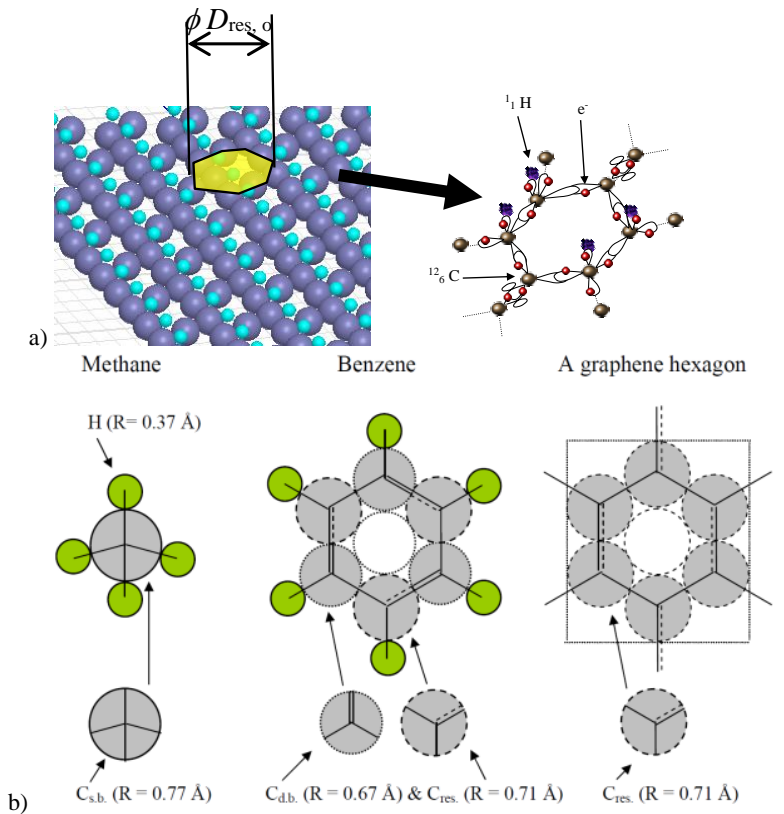

Fig. 6. Model of the geometrical structures of selected carbon nanomaterials. a) graphane; b) the dimensions of the basic element of graphene

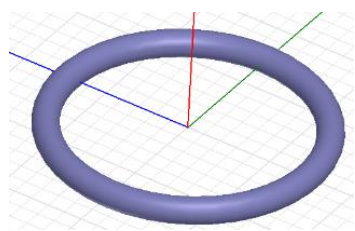

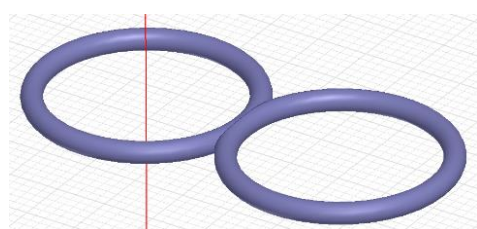

b)

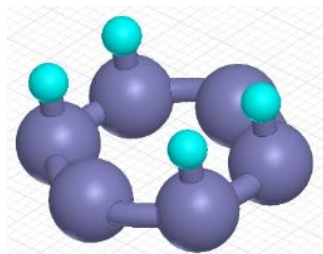

Fig. 7. Simplified geometrical model of the basic "benzene core" elements for carbon nanomaterial structures: a) benzene; $b$ ) double benzene; $c$ ) benzene core of a graphane structure

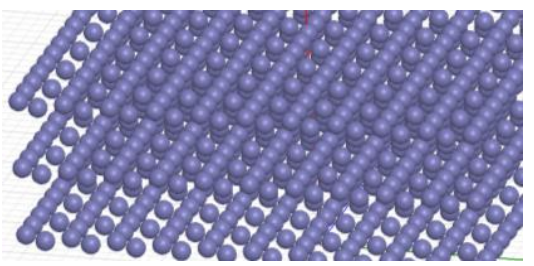

Fig. 8. Geometrical model of the three-layered structure of a graphene nanomaterial (graphite)

In the numerical analyses and their evaluation, we assume the basic forms of an excited (index 1) and a generated (index 2) electromagnetic wave, each having a forward and a backward component (whose electric intensities are denoted by $E_{f}$ and $E_{b}$, respectively).
The vectors of the electric field of the electromagnetic wave are expressed as:

$$
\begin{aligned}
& \boldsymbol{E}_{1}(t, x, y, z)= \\
& =\boldsymbol{E}_{1 f}(x, y, z) \cdot e^{-j \omega_{1} t+\varphi} \cdot e^{\underline{k}_{1} \mathbf{n}_{1} \cdot r_{1}}+ \\
& +\boldsymbol{E}_{1 b}(x, y, z) \cdot e^{+j \omega_{1} t+\varphi} \cdot e^{\underline{k}_{1} \mathbf{n}_{1} \cdot r_{1}} \\
& \boldsymbol{E}_{2}(t, x, y, z)= \\
& =\boldsymbol{E}_{2 f}(x, y, z) \cdot e^{-j \omega_{2} t+\varphi} \cdot e^{\underline{k}_{2} \mathbf{n}_{2} \cdot r_{2}}+ \\
& +\boldsymbol{E}_{2 b}(x, y, z) \cdot e^{+j \omega_{2} t+\varphi} \cdot e^{\underline{k}_{2} \mathbf{n}_{2} \cdot \boldsymbol{r}_{2}}
\end{aligned}
$$

where $x, y, z$ are the coordinates of a point in the Cartesian coordinate system; $t$ denotes the time; $\omega$ represents the angular frequency; $\boldsymbol{n}$ is the normal vector of the direction of the electromagnetic wave propagation; $\underline{k}$ stands for the comprehensive notation of the wave number; $\boldsymbol{r}$ represents the position vector of the source of the electromagnetic wave and, if related to the origin, denotes the coordinates of the point at which a component is evaluated; index 1 expresses the classification of an excited electromagnetic wave; and index 2 specifies the actual oscillation system (such as a modeled structure, atom, and molecule). These procedural instruments and approaches are known from quantum mechanical models, including, for example, that proposed by Bina [3] for the Rabi oscillation, Fig. 9; in this context, the referenced paper [3] presents an example of the interference between an incident electromagnetic wave and the oscillation of the actual system, Fig. 10.

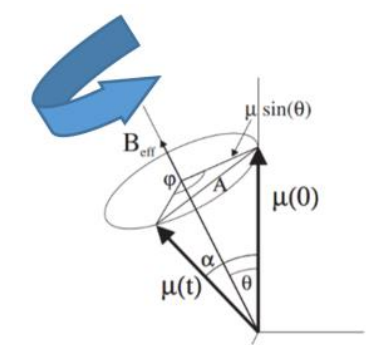

Fig. 9. Model of the atom and the magnetic moment $\mu(t)$

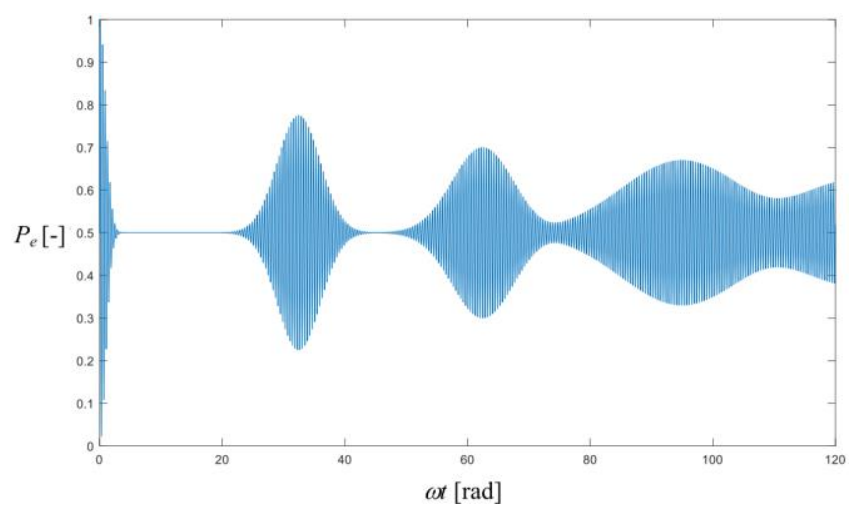

Fig. 10. Resulting shape of the "Rabi oscillations" relating to an external source of an electromagnetic wave

Principally, the interference process thus consists in identifying the relationships between two oscillating systems, namely, an oscillator and an electromagnetic wave generated by an oscillating object exhibiting a physical similarity known in Rabi oscillations [3]. The ratio of frequencies, $m_{\mathrm{M}}$, can then be employed to evaluate the parameters and types of models that will enable the analysis (ad 1-4, formulas (2), (3)):

$$
\begin{gathered}
m_{M, a b s}=\frac{\left|\omega_{1}-\omega_{2}\right|}{\omega_{2}}, \\
m_{M}=\frac{\left(\omega_{1}-\omega_{2}\right)}{\omega_{2}} .
\end{gathered}
$$


The proportional relationships characterized in (4), (5) for the frequencies $m_{\mathrm{M}}$ yield:

$$
\begin{gathered}
\omega_{1} \ll \omega_{2}, \\
\omega_{1} \leq \omega_{2}, \\
\omega_{1} \cong \omega_{2} \vee \omega_{1}=m \omega_{2}, m=2,3, . ., N^{\circ} .
\end{gathered}
$$

The distribution of the effects and frequency bands defining the electromagnetic waves' interference (9) $\boldsymbol{E}_{\text {coupl }}$ can be written for two coupled waves as:

$$
\begin{aligned}
& \boldsymbol{E}_{\text {coupl }}(t)=\boldsymbol{E}_{1 f}(x, y, z) \cdot e^{-j \omega_{1} t+\varphi_{1}} \cdot e^{\underline{k}_{1} \mathbf{n}_{1} \cdot r_{1}}+ \\
& \boldsymbol{E}_{1 b}(x, y, z) \cdot e^{+j \omega_{1} t+\varphi_{1}} \cdot e^{\underline{k}_{1} \mathbf{n}_{1} \cdot \boldsymbol{r}_{1}}+ \\
& \boldsymbol{E}_{2 f}(x, y, z) \cdot e^{-j \omega_{2} t+\varphi_{2}} \cdot e^{\underline{k}_{2} \mathbf{n}_{2} \cdot r_{2}}+ \\
& \boldsymbol{E}_{2 b}(x, y, z) \cdot e^{+j \omega_{2} t+\varphi_{2}} \cdot e^{\underline{k}_{2} \mathbf{n}_{2} \cdot \boldsymbol{r}_{2}}
\end{aligned}
$$

where $\boldsymbol{E}_{\mathrm{f}}, \boldsymbol{E}_{\mathrm{b}}$ are the forward and backward vector components of the intensity of the electric field of an electromagnetic wave in the assumed system (the periodic system of the structure), and $\boldsymbol{E}_{1}$ denotes the component of the external source of the incident electromagnetic wave's intensity vector; such a description allows us to characterize the known interference effects. For conditions (6), (7), and (8), we then have the interference and, if the waves are coherent, also the resonance effects.

When characterizing the two basic, mutually interfering electromagnetic waves (2), (3) according to their impact on the measured structure, we can categorize them into the impinging $\left(\boldsymbol{E}_{\mathrm{f}}\right)$ and the reflected groups, enabling us to evaluate the structural properties via the parameters of the impedance matrix $(\boldsymbol{Z})$ or the scattering matrix $(\boldsymbol{S})$. These parameters will then allow the tested model to be analyzed within the frequency spectrum in relation to the preset number of ports. For two ports, the scattering parameters are:

$$
\begin{aligned}
& \boldsymbol{E}_{1 \mathrm{~b}}=s_{11} \cdot \boldsymbol{E}_{1 \mathrm{f}}+s_{12} \cdot \boldsymbol{E}_{2 \mathrm{f}}, \\
& \boldsymbol{E}_{2 \mathrm{~b}}=s_{21} \cdot \boldsymbol{E}_{1 \mathrm{f}}+s_{22} \cdot \boldsymbol{E}_{2 \mathrm{f}} .
\end{aligned}
$$

Based on the formulas, it is then possible to define the individual $S$ parameters, as follows:

$$
\begin{aligned}
& s_{11}=\boldsymbol{E}_{1 \mathrm{~b}} \boldsymbol{E}_{1 \mathrm{f}}{ }^{-1} \mid \boldsymbol{E}_{2 \mathrm{f}}=\mathbf{0} \text { the input reflection coefficient; } \\
& s_{12}=\boldsymbol{E}_{1 \mathrm{~b}} \boldsymbol{E}_{2 \mathrm{f}}^{-1} \mid \boldsymbol{E}_{1 \mathrm{f}}=\mathbf{0} \quad \text { the backward transmission } \\
& s_{21}=\boldsymbol{E}_{2 \mathrm{~b}} \boldsymbol{E}_{1 \mathrm{f}}^{-1} \mid \boldsymbol{E}_{2 \mathrm{f}}=\mathbf{0} \quad \text { the transmission coefficient; } \\
& s_{22}=\boldsymbol{E}_{2 \mathrm{~b}} \boldsymbol{E}_{2 \mathrm{f}}{ }^{-1} \mid \boldsymbol{E}_{1 \mathrm{f}}=\mathbf{0} \quad \text { and the output reflection } \\
& \text { coefficient. } \\
& z_{12}=\boldsymbol{E}_{1 \mathrm{~b}} \boldsymbol{H}_{2 \mathrm{f}}{ }^{-1} \mid \boldsymbol{H}_{1 \mathrm{f}}=\mathbf{0} \quad \text { the backward transmission } \\
& z_{21}=\boldsymbol{E}_{2 \mathrm{~b}} \boldsymbol{H}_{1 \mathrm{f}}{ }^{-1} \mid \boldsymbol{H}_{2 \mathrm{f}}=\mathbf{0} \quad \text { the transmission coefficient; } \\
& z_{22}=\boldsymbol{E}_{2 \mathrm{~b}} \boldsymbol{H}_{2 \mathrm{f}}{ }^{-1} \mid \boldsymbol{H}_{1 \mathrm{f}}=\mathbf{0} \quad \text { and the output reflection }
\end{aligned}
$$

\section{Modeling the parameters of a periodic structure}

In order to design the geometries of the models capturing the investigated carbon-based periodic structures (Fig. 5), it is necessary to define the initial and boundary conditions of the given model and the sources of the electromagnetic field The basic formation of a stochastic model to represent an element of a periodic structure consists in describing the atomic bonds and the region where an atom may occur; the motion of the valence electrons is displayed in Fig. 6 (extreme left). Another step in setting the conditions of the model requires us to evaluate the components of the electric field $E$ intensity vector in the basic geometrical element $E_{\mathrm{r}}$. To facilitate simple estimation of the order of magnitude of the intensities, we can - for the hydrogen atom $\mathrm{H}$ bound to carbon $\mathrm{C}$ and one binding electron in the middle electrodes of the coaxial arrangement of the internal structure (Fig. 6, Fig. 11) - evaluate the radial potential electric field intensity from the single $\mathrm{C}-\mathrm{H}$ bond as:

$$
\begin{gathered}
E_{r, a}=\frac{1}{4 \pi \varepsilon_{0}} \cdot \frac{q_{e}}{\left|R_{1}\right|^{2}}, \\
E_{r, a}=\frac{1}{4 \pi \cdot 8.856 \cdot 10^{-12}} \cdot \frac{1.602 \cdot 10^{-19}}{\left(0.71 \cdot 10^{-10}\right)^{2}}= \\
2.937 \cdot 10^{11} \mathrm{~V} / \mathrm{m}\left(2.937 \cdot 10^{2} \mathrm{~V} / \mathrm{nm}\right)
\end{gathered}
$$

where $R_{1}$ is the radius of the modeled elements. Similarly to the approach adopted in [6] and [30], the analysis of the structure was based on models for solving the telegrapher's equations $[6,11,19]$.

\section{Relativity effect in the carbon structure models}

The known models $[6,11,15,25]$ allow us to express changes of the electromagnetic field in dependence on the motion of the system A relative to its counterpart $\mathrm{A}^{\prime}$. Let us assume that an external electromagnetic wave in the system $\mathrm{A}$ and the modeled structure together constitute the systems $\mathrm{A}$ and $\mathrm{A}^{\prime}$; the analysis of the models classified via ad A) $f_{\mathrm{t}} \in\left\langle 1 \cdot 10^{6} ; 500 \cdot 10^{9}\right\rangle[\mathrm{Hz}]$, $f_{\mathrm{a} 1} \approx 2 \cdot 10^{13}[\mathrm{~Hz}]$ then depends on the modified current density $\boldsymbol{J}$ and the intensities of the electric and magnetic fields, $\boldsymbol{E}$ and $\boldsymbol{H}$ $[6,11]$. For the unabbreviated expression, respecting the element motion at a velocity $v$ in all directions, the current density in relation to the moving system $\mathrm{A}^{-\mathrm{A}^{\prime}}$ can be subsequently written as:

$$
\boldsymbol{J}_{S \square}=\frac{J_{\mathrm{x}}^{\prime}-v_{x} \operatorname{div}\left(\frac{\varepsilon^{\prime}}{\gamma^{\prime}} \boldsymbol{J}_{\Delta}^{\prime}\right)}{\sqrt{1-\left(\frac{v}{c}\right)^{2}}} \boldsymbol{u}_{x}+
$$$$
+\frac{J_{\mathrm{y}}^{\prime}-v_{y} \operatorname{div}\left(\frac{\varepsilon^{\prime}}{\gamma^{\prime}} \boldsymbol{J}_{\Delta}^{\prime}\right)}{\sqrt{1-\left(\frac{v}{c}\right)^{2}}} \boldsymbol{u}_{y}+\frac{J_{\mathrm{z}}^{\prime}-v_{z} \operatorname{div}\left(\frac{\varepsilon^{\prime}}{\gamma^{\prime}} \boldsymbol{J}_{\Delta}^{\prime}\right)}{\sqrt{1-\left(\frac{v}{c}\right)^{2}}} \boldsymbol{u}_{z}+
$$

$$
+j \frac{c \operatorname{div}\left(\frac{\varepsilon^{\prime}}{\gamma^{\prime}} J_{\Delta}^{\prime}\right)-\frac{v_{x}}{c} J_{x}^{\prime}-\frac{v_{y}}{c} J_{y}^{\prime}-\frac{v_{z}}{c} J_{z}^{\prime}}{\sqrt{1-\left(\frac{v}{c}\right)^{2}}} \boldsymbol{u}_{t}
$$

The formula for the value of the electric volume charge density $\rho$ reads:

$$
\rho=\frac{\rho-\frac{v_{\Delta}}{c^{2}} J_{S \Delta}^{\prime}}{\sqrt{1-\left(\frac{v}{c}\right)^{2}}}
$$

In (21) and (22), $v$ represents the relative motion with an instantaneous velocity of the moving system $\mathrm{A}, \boldsymbol{v}_{\Delta}$ is the relative motion vector with components $v_{\mathrm{x}}, v_{\mathrm{y}}, v_{\mathrm{z}}$ in the Cartesian coordinate system $\mathrm{A}, \boldsymbol{u}_{\mathrm{x}}, \boldsymbol{u}_{\mathrm{y}}, \boldsymbol{u}_{\mathrm{z}}$ are its base vectors, $\boldsymbol{J}_{\Delta}^{\prime}$ is the current density vector in system $\mathrm{A}^{\prime}$ with components $J_{\mathrm{x}}{ }^{\prime}, J_{\mathrm{y}}{ }^{\prime}, J_{\mathrm{z}}{ }^{\prime}, c$ represents the speed of light in a vacuum, $\rho, \rho^{\prime}$, are the volume densities of the electric charge in the system $\mathrm{A}$ and $\mathrm{A}^{\prime}$, respectively, $\boldsymbol{J}_{\mathrm{S}}$, is the total current density vector in system A, $\boldsymbol{J}_{\mathrm{S} \Delta}^{\prime}$ is the current density vector in system $\mathrm{A}^{\prime}, \gamma^{\prime}$ is the specific electrical conductivity of an environment from the macroscopic view in system $\mathrm{A}^{\prime}$, and $\varepsilon^{\prime}$ is the electric permittivity from the point of view of the system $A^{\prime}$.

As regards electrical engineering, relativistic effects are known especially in signal transmission within radar technology [21, 29, 47, 51]. According to the above example, [25], the effects manifest themselves in electromagnetic fields of dynamic systems from speeds in the order of $1 \mathrm{~m} / \mathrm{s}[11,15]$. 
In precise nanometric analyses, such effects have to be individually considered and respected, through the perspective of the above conditions (1) ad A), ad B).

\section{Relativity limit parameters of the electromagnetic model of a carbon-based periodic structure}

The standard approach to modeling structures with a probabilistic distribution of the electric charge in atomic parts is usable in analyses centered on the evaluation of the frequency spectrum of the parameters $S$ and $Z$; this procedure can also be employed to evaluate, as outlined in formulas (9-20), models of chemical elements and compounds, including that of the benzene nucleus (Figs. 11-13). Within such models, it is possible to consider the impact exerted on the parameters of the spectrum by the geometrical configuration of the "motion" of the electric charge $q$ in the structure of the modeled elements. The modelingbased results may then be compared with those of the experiments to determine the overall match. This classic approach to numerical model creation has been widely employed $[2,6,11,14,15,18,21$, $25,29,33,35,36,42,47,51,52]$, as also shown through the relevant criterion (1) ad A). To perform the associated qualitative analysis, it is convenient to use the classification embodied in the above precondition (1), ad B), which covers the behavior of the dynamic system inside the modeled structure; for cases of strong coupling between the internal and the external electromagnetic fields, some basic aspects of the modeled object are comprised, too. The geometry of the models, Fig. 11, Fig. 12, Fig. 13, and their dimensions were chosen according to the work of $\mathrm{R}$. Heyrovska [26, 27, 28].

The design of the geometrical model for the frequency range B) can be characterized in greater detail as suggested in Fig. 14. The fundamental element of the graphene-based periodic structure is a hexagonal carbon nucleus [50]; from the perspective of the stochastic distribution of the instantaneous position and arrangement of carbon $\mathrm{C}$ valence electrons, the fundamental element and bonds can be schematically described as shown in Fig. 15.

The applicability of the designed nanometer structures in electrical signal transmission is strongly dependent on both the structures' ability to transmit high-quality signals (parametrically expressed via indicators such as the $\mathrm{S} / \mathrm{N}$ ratio, $[2,7,17,18,52]$ ) along the system's surface and the limit properties of the input electric current $i_{\mathrm{s}}(\mathrm{t})$. We have:

$$
i_{s}(t)=\frac{d\left(q \cdot n_{q}\right)}{d t}, i_{s}(t)=\frac{q \cdot n_{q}}{\Delta \ell} \cdot v_{o k} \cdot e^{-\frac{q}{k T} u_{r, u}},
$$

where $q$ is the electric charge of an elementary object, $n_{\mathrm{q}}$ is the number of elementary objects in the observed volume, $i_{\mathrm{s}}(\mathrm{t})$ is the instantaneous value of the electric current, $\Delta \ell$ is the element of length, Fig. 15a, $v_{\text {ok }}$ is the mean speed of movement of an electrically charged object, $u_{\mathrm{r}, \mathrm{u}}$ is the voltage on the elementary path of an electric charge $q, k$ is the Boltzmann constant, and $T$ is the temperature.

In the periodic structure $[8,12,13,16,20,32,35,46]$ composed of basic elements according to Figs. 1, 2, 3, and 4 and schematically illustrated in Fig. 14, it is possible to estimate the electric current $i_{\mathrm{s}, \max }(\mathrm{t})$ from the motion (at speed $v_{\mathrm{ok}}$ ) of the bonding electron's electric charge $q_{\mathrm{e}}$ and binding particles $n_{\mathrm{q}}$ (in accordance with the Bohr-Sommerfeld Theory [36]). We thus have:

$$
\begin{gathered}
i_{s, \max }(t)=\frac{q_{e} \cdot n_{q}}{\Delta \ell} \cdot v_{o k}, i_{s, \max }(t)=0.364 \cdot 10^{-9}[\mathrm{~A}], \\
J_{s, \max }=\frac{i_{s, \max }}{S}=\frac{0.364 \cdot 10^{-9}}{1.539 \cdot 10^{-20}}= \\
23.66 \cdot 10^{9}\left[\mathrm{~A} / \mathrm{m}^{2}\right]\left(23.66\left[\mathrm{nA} / \mathrm{nm}^{2}\right]\right)
\end{gathered}
$$

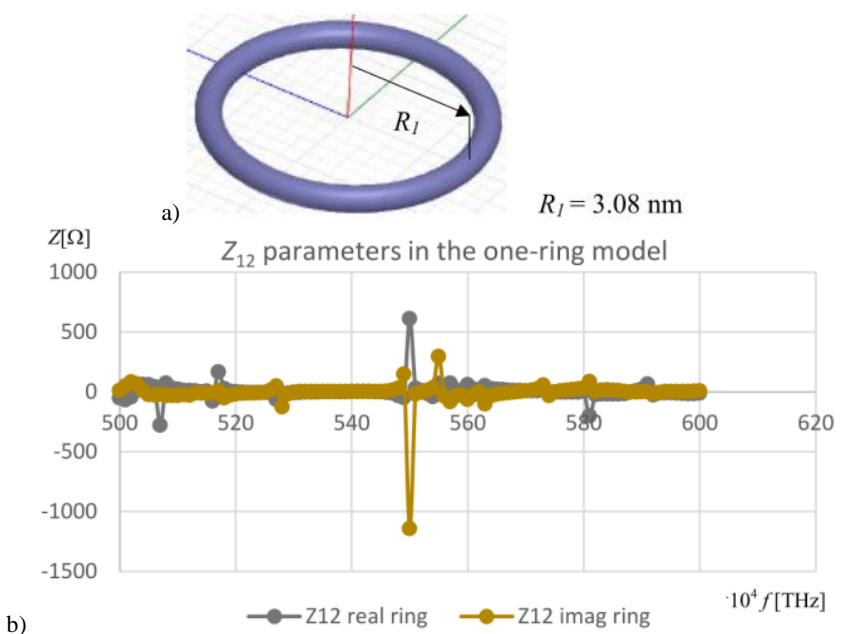

Fig. 11. Simplified geometrical model of the basic "benzene core" elements for carbon nanomaterial structures: a) benzene; b) spectral analysis of the $Z$ parameters

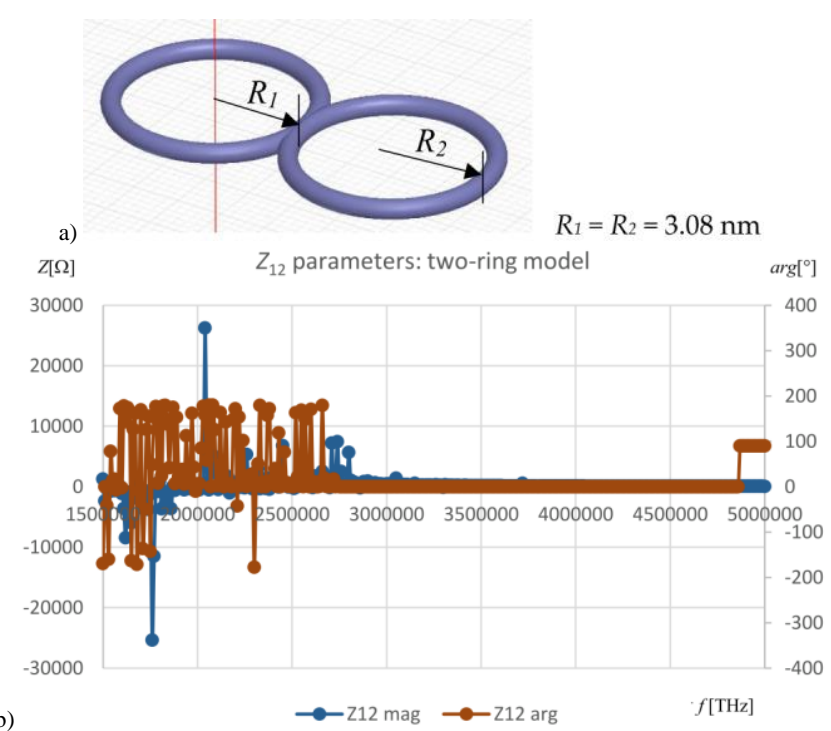

Fig. 12. Simplified geometrical model of the basic "benzene core" elements for carbon nanomaterial structures: a) double benzene; $b$ ) spectral analysis of the $Z$ parameters

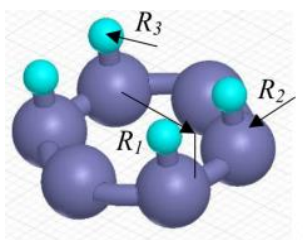
$R_{1}=3.08 \mathrm{~nm}, R_{2}=0.077 \mathrm{~nm}, R_{3}=0.037 \mathrm{~nm}$ $Z[\Omega$ $Z_{12}$ parameters: one-element graphane mode

$\arg \left[{ }^{\circ}\right]$

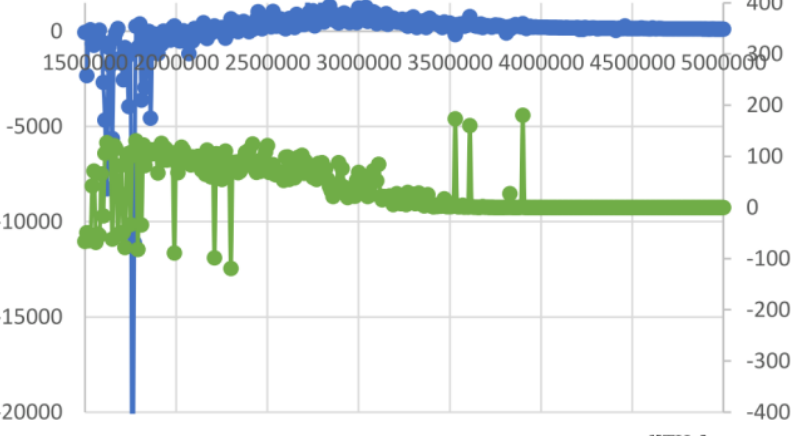

Fig. 13. Simplified geometrical model of the basic "benzene core" elements for carbon nanomaterial structures: a) double benzene; b) spectral analysis of the $Z$ parameters 
From this current, we can then express the current density $\boldsymbol{J}$ caused by the given bonds (Fig. 15). If the density is known, models exploiting the solution of Maxwell's equations allow establishing, via stochastic simulation of a periodic element (Fig. $15 \mathrm{~b}$ ), the hypothetical current density $\boldsymbol{J}_{\mathrm{ext}}$ of an external electromagnetic field; this density originates from, for example, the transmission of an EMG wave along a periodic structure. The condition when a temporary or permanent alteration (rearrangement) may occur in the basic element of the structure, Fig. 15b, then embodies a critical stage for the model. The formula for the potential condition expressed by the intensity $E_{\mathrm{r}, \mathrm{a}}$ enables us to express, from the known electric current magnitude (30) and density (31), the actual intensity of the electric field of the modeled and analyzed periodic structure; such intensity is generated by the propagation of a longitudinal electromagnetic wave. We have:

$$
\begin{aligned}
& E_{t}=\frac{1}{4 \pi \varepsilon_{0}} \cdot \frac{d q_{e}}{|d \ell|^{2}}, E_{t}=\frac{1}{4 \pi \cdot \varepsilon_{0}} \frac{d q_{e}}{d \ell} \frac{1}{d \ell}, \\
& E_{t}=\frac{1}{4 \pi \cdot \varepsilon_{0}} \frac{i_{s}}{v_{o k}} \frac{1}{d \ell}, E_{t}=2.937 \cdot 10^{2}[\mathrm{~V} / \mathrm{nm}]
\end{aligned}
$$

where $E_{\mathrm{t}}$ is the tangential component of the electric intensity along the considered bound, Fig. 15b. The quantities thus expressed then facilitate determining the macroscopic quantity, or the specific electrical conductivity, of the periodic structure:

$$
\begin{gathered}
\gamma=\frac{J_{s, \max }}{E_{t}}, \gamma=\frac{i_{s, \max }}{S} \frac{4 \pi \varepsilon_{0} v_{o k} d \ell}{i_{s, \max }}, \\
\gamma=\frac{4 \pi \varepsilon_{0} v_{o k}}{\pi d \ell^{2}} d \ell, \gamma=\frac{4 \pi \varepsilon_{0} n_{q} q^{e}\left(\frac{1}{4 \pi \varepsilon_{0} m_{0} d \ell}\right)^{\frac{1}{2}}}{\pi d \ell}, \\
\gamma=2 n_{q} q^{e} \frac{\left(\frac{\varepsilon_{0}}{\pi m_{0}}\right)^{\frac{1}{2}}}{d \ell^{\frac{3}{2}}}, \gamma=9.623[\mathrm{~S} / \mathrm{nm}]
\end{gathered}
$$

Further steps within the procedure are aimed at finding an external electromagnetic field having an intensity $E_{\text {ext,c }}$ at which the periodic structure of the designed system and its electromagnetic properties change temporarily. A temporary rearrangement of the element's bonds facilitates restoring or resetting the properties of the structure; a permanent change (when the value of $E_{\text {ext,c }}$ is exceeded), however, will not enable such restoration. The value of the electric intensity $E_{\text {ext,c }}$ is related to the permissible maximum current density at which the nanostructure can be stressed without permanent damage. Therefore, this parameter is related to the lifetime of the target application using a periodic nanostructure. In the discussed case, the monitored parameter can be obtained through an experimental measurement of the speed $v_{\mathrm{w}}$ of the electromagnetic wave propagation along the periodic structure (Fig. 5a, b, c, d, Fig. 8); the relevant propagation behavior is shown in Fig. 16.

Using the above-presented specifications, it is then possible to perform a numerical analysis and to evaluate the parameters of the periodic system from the perspective of the properties of an electromagnetic field having anticipated limit parameters, which, generally, are desirable in nanoelectric systems designed to transmit or process signals along carbon-based structures. The parameters embody a fundamental prerequisite for planning the service life of a periodic structure [20] and the superior nanoor microelectronic element. The numerical model was solved with ANSYS-HFSS for the frequency range A) (for $\boldsymbol{E}_{1 \mathrm{f}}=1 \mathrm{~V} / \mathrm{m}$ ) and ANSYS-EMAG [1], the APDL language, in the frequency range $\mathrm{B}),[1,8,12,13,16,20,21,22,23,46,49]$.

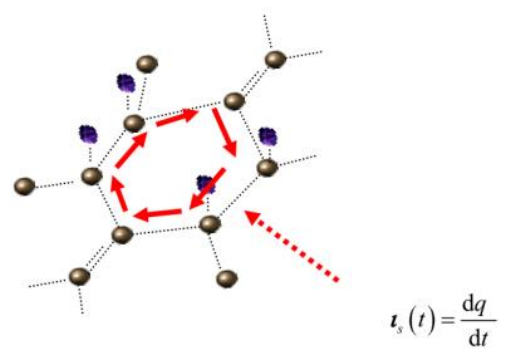

Fig. 14. Simplified expression of the electric currents in an element of the periodic structure

a)

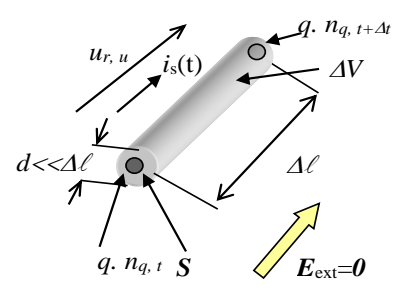

b)

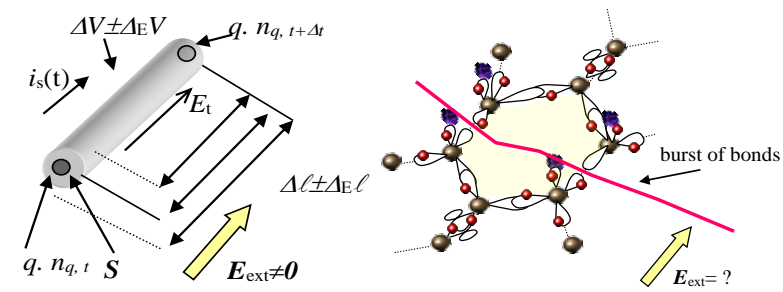

Fig. 15. Bonding details: a) model of an electron moving in the basic element of a carbon structure; $b$ ) changes due to an external electromagnetic field

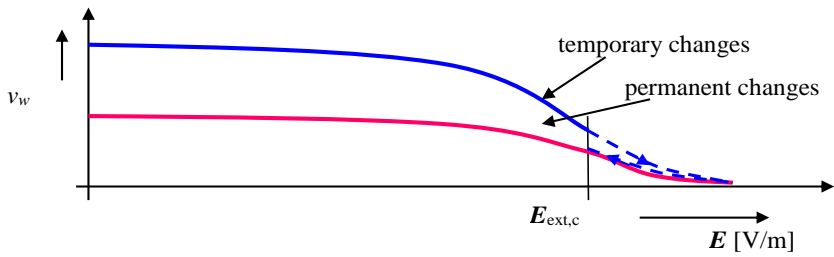

Fig. 16. Anticipated speeds of a surface electromagnetic wave propagation along a carbon-based periodic structure

The relative permittivity $\varepsilon_{\mathrm{r}}$, a macroscopic parameter to facilitate the modeling of electromagnetic quantities outside the model of the atom and its vicinity, is obtainable via a simple assumption: In two neighboring atoms bound by electrostatic forces, the mutual force from Coulomb's law can be evaluated for the condition $r_{\mathrm{a}}<<R_{12}$ (Fig. 17) as:

$$
\boldsymbol{F}_{12}=\frac{1}{4 \pi \cdot \varepsilon_{0}} \frac{q_{1 e} q_{2 e}}{\left\|\boldsymbol{R}_{12}\right\|} \boldsymbol{u}_{r},
$$

where $q_{1 \mathrm{e}}, q_{2 \mathrm{e}}$, are the electric charges (electrons) in the "benzene core" nanostructure; $\boldsymbol{R}_{12}$ represents the vector of the distance between the atomic centers; and $\boldsymbol{F}_{12}$ denotes the vector of the electromagnetic force acting between atoms 1 and 2, Fig. 17; in which they are $\boldsymbol{E}_{1}, \boldsymbol{E}_{2}$, the intensity vectors of the electric fields of atoms 1 and 2; and $r_{\mathrm{a} 1}, r_{\mathrm{a} 2}$ stand for the radii of atoms 1 and 2 . After satisfying the conditions $r_{\mathrm{a} 1} \ll<R_{12}, r_{\mathrm{a} 2} \ll R_{12}$, we can interpret the effects in Fig. 17 as forces between the point charges represented by atoms 1 and 2, considering, for example, the case where $q_{1 \mathrm{e}}$ elementary charge 1 is defined by $n_{\mathrm{e} 1}=1$, the electric charge of atom 2 (carbon, C) is defined by $q_{2 \mathrm{e}}$ and $n_{\mathrm{e} 2}=4$; we then have:

$$
\boldsymbol{F}_{12}=\frac{1}{4 \pi \cdot \varepsilon_{0}} \frac{q_{1 e} n_{e 1} q_{e} n_{e 2}}{\left\|\boldsymbol{R}_{12}\right\|} \boldsymbol{u}_{r} .
$$

where $n_{e 1}, n_{e 2}$ denote the amounts of electrons in the shells of atoms 1 and 2, Fig. 17. Upon comparing the formulas (29), (30), 
and based on Gauss's theorem, the relative permittivity of atom 2 is expressed via:

$$
\begin{gathered}
\Phi_{e 2}=\oint_{S\left(r_{a 2}\right)} \frac{1}{4 \pi \cdot \varepsilon_{0}} \frac{q_{2 e} n_{e 2}}{\left\|\boldsymbol{r}_{a 2}\right\|^{2}} \boldsymbol{u}_{r} \cdot d \boldsymbol{S}_{a 2}, \\
\Phi_{e 2}=\int_{S(r)} \frac{1}{4 \pi \cdot \varepsilon_{0}} \frac{n_{e 2} q_{2 e}}{\left\|\boldsymbol{r}_{a 2}\right\|^{2}} \boldsymbol{u}_{r} \cdot d \boldsymbol{S}, \\
\Phi_{e 2}=\int_{S(r)} \varepsilon_{r} E_{r} \boldsymbol{u}_{r} \cdot d \boldsymbol{S}, \\
\varepsilon_{r}=n_{e 2},
\end{gathered}
$$

where $E_{\mathrm{r}}$ is the radial component of the electric intensity, $\varepsilon_{\mathrm{r}}$ is the relative permittivity, $\boldsymbol{u}_{\mathrm{r}}$ is the base vector of a spherical coordinate system, and $S(r)$ is the surface of the sphere depending on the radius $r$.

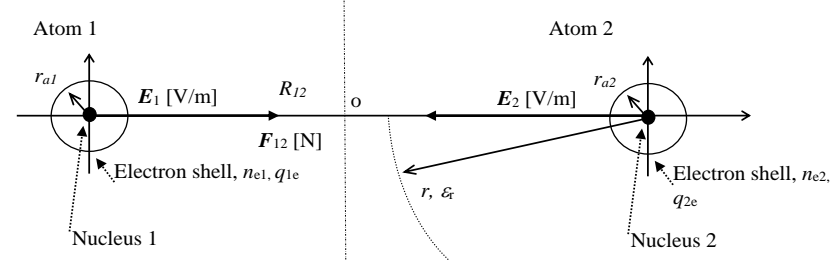

Fig. 17. Scheme of the atomic forces to facilitate relative permittivity evaluation

a)
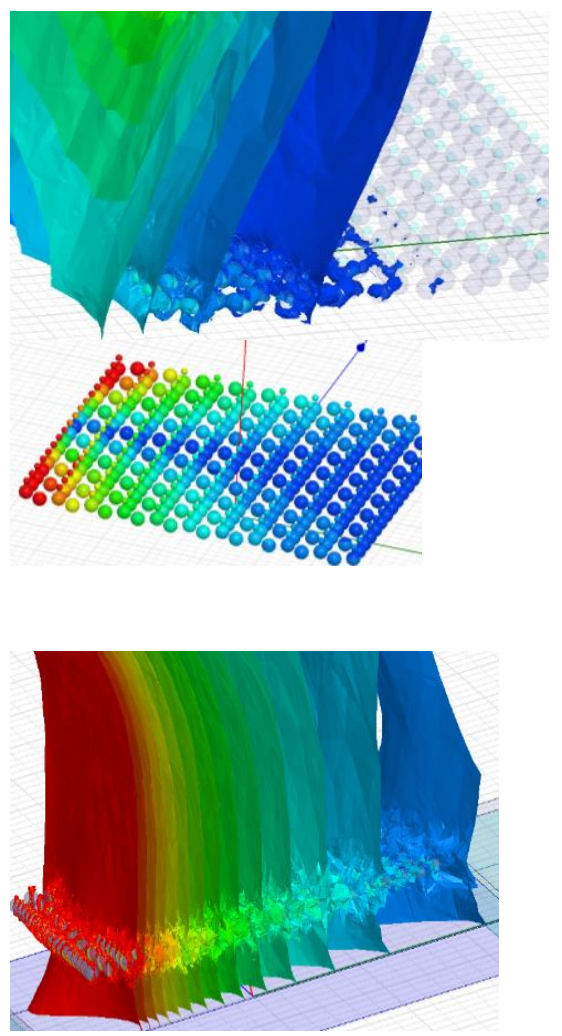

E Field $\left[y_{-}\right.$per_m $5.1348 e+\square 10$
$4.8139 e+\square 10$
$4.4930 e+\square 10$
$4.1721 e+\square 10$
$3.8511 e+\square 10$
$3.5302 e+\square 10$
$3.2093 e+\square 10$
$2.8884 e+\square 10$
$2.5674+\square 10$
$2.2465 e+\square 10$
$1.9256 e+\square 10$
$1.6946 e+\square 10$
$1.2837 e+\square 10$
$9.6278 e+\square 09$
$6.4186 e+\square 09$
$3.2093 e+\square 09$
$1.6795 e+\square 04$

E Field[v $v_{-}$per_n

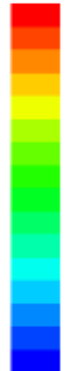

5. $1348 c+8 a 9$ 4. $49136+699$ 4. $40136+635 \mathrm{e}+80$ S. $6677 \varepsilon+009$ 3. $30196+899$ 2. $9342 e+0 a 9$ 2. $5674 \mathrm{e}+009$ 2. 2005e+8a9 2. $2006 \mathrm{cos}+829$ $1.4671 \mathrm{~s}+089$ $1.1003 c+60$ 1983c+8a9 3. $66786+098$ 1. $54736+993$

\section{Modeling, analyzing, evaluating, and experimenting with the organic structures}

As indicated above, the basic model is built by exploiting a FEM-based system, namely, ANSYS [1], and enables us to find the geometry and parameters of the target structure with respect to its chemical survivability.

We conducted diverse numerical analyses of periodic system models, assuming precondition (1); relevant outcomes are illustrated in Fig. 5a-c and Fig. 5d-e for the frequency domains A) and B), respectively.

The elementary structure according to Figs. 5, 6, and 14 was chosen and solved (Figs. 18-20) as the basis of the numerical model introduced in the above formulas (5-9) for the frequency range A) and (14) for the frequency range B); the model analysis was processed in the batch mode. In order to design the geometry of the models of the carbon-based periodic structures (Figs. 5 and 6), it is necessary to define the corresponding initial and boundary conditions and the sources of the electromagnetic field. The basic formation (an element of the periodic structure) can be simply described by the atomic bonds, namely, the motion of the valence electrons (Fig. 6 and Fig. 14). In the case of using the periodic nanostructure as the electric line material $[7,17,20]$, the movement of electrons is taken into account as a source of unwanted signal, i.e., noise. Therefore, it is necessary to evaluate the components of the electromagnetic field caused by the motion of the electric charges of the nanostructure with respect to the components of the transmitted EMG waves.

b)

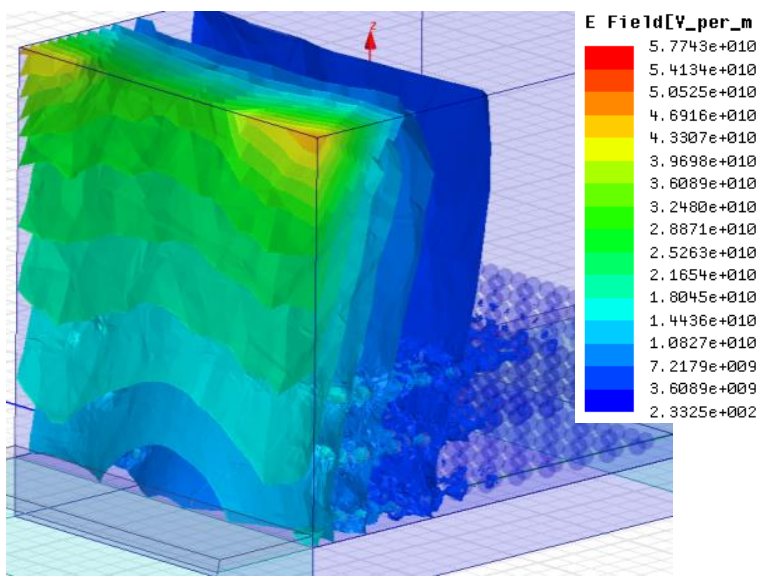

d)

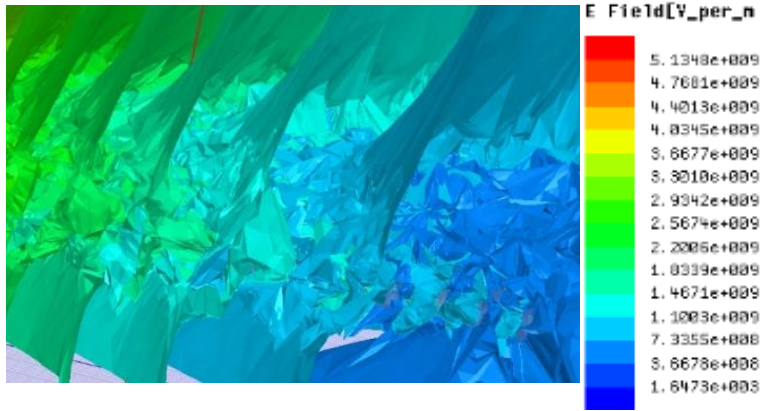

Fig. 18. Distribution of the intensities of an incident electromagnetic wave's electric component E in: a) graphane; b) graphite; c) graphene; d) the close vicinity of the graphene structure 
a)

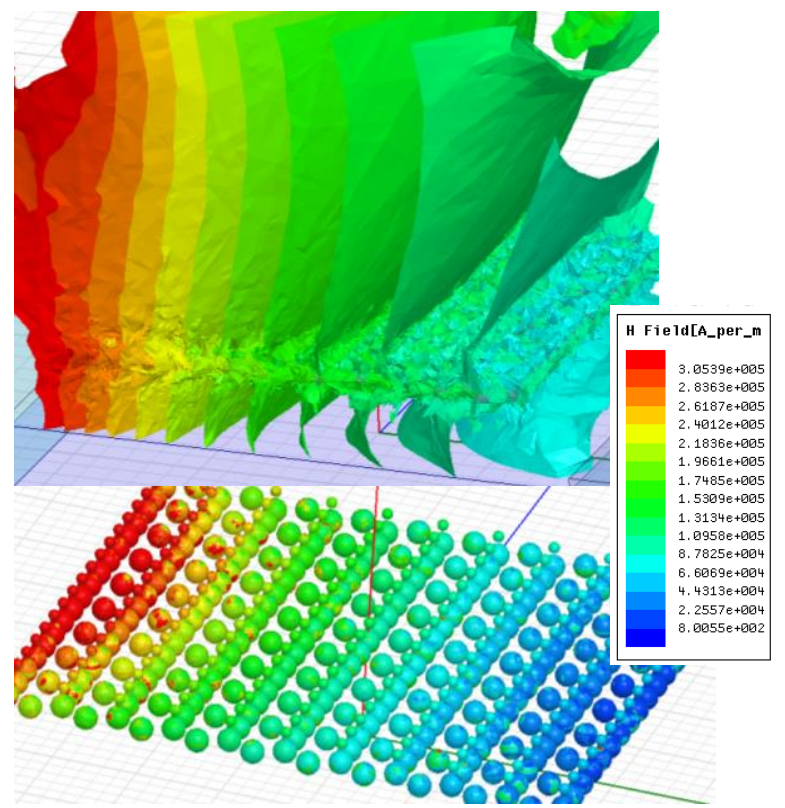

b)

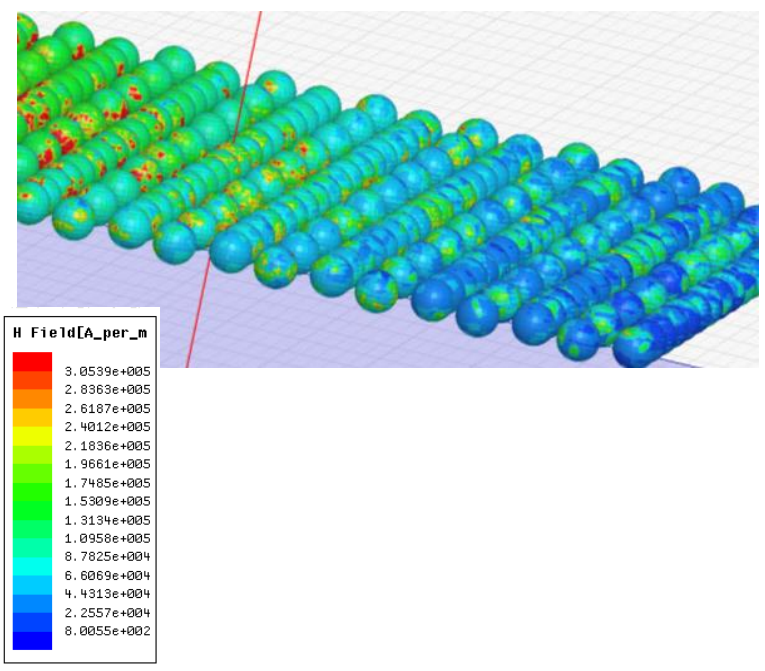

Fig. 19. The distribution of the intensities of an incident electromagnetic wave's magnetic field $H$ in a) the close vicinity of graphane; $b$ ) graphene atoms
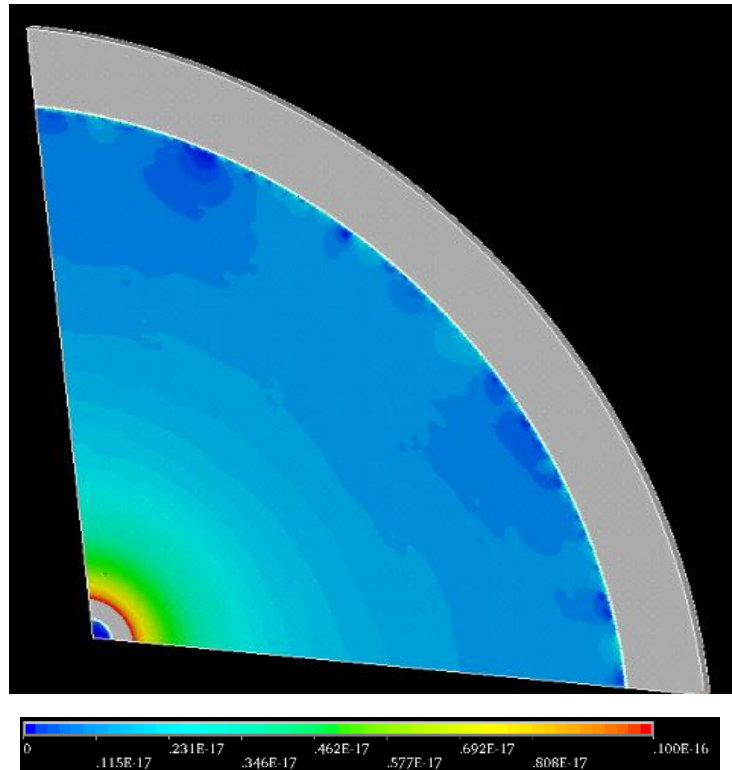
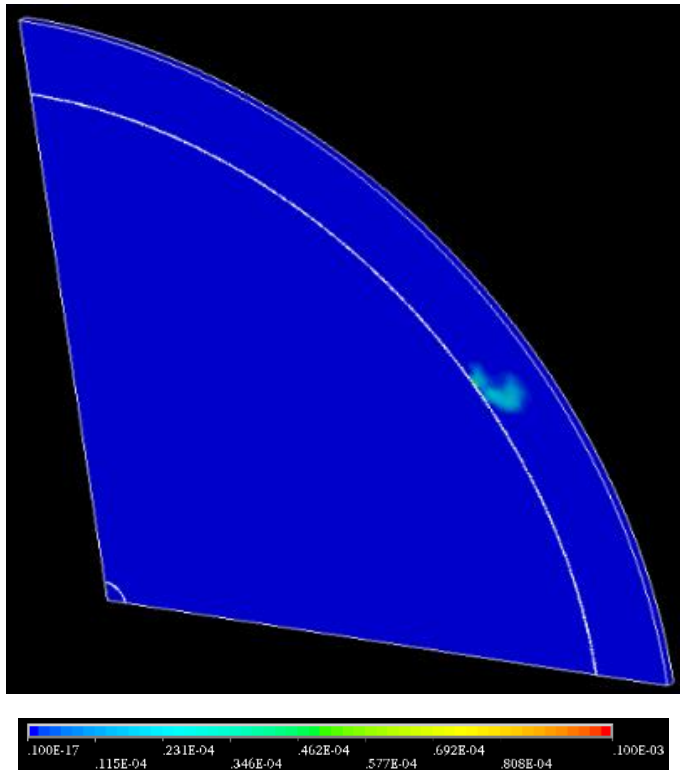

Fig. 20. Distribution of a) the electric intensity $E[\mathrm{~V} / \mathrm{m}]$ in coaxially arranged graphane electrodes; $b$ ) the magnetic flux density $B[T]$ in signal transmission at current $i=1 \mu A$

Within the macroscopic model, both the maximum signal transmitted by the designed graphene-based polymer structure and the tangential electric strength are estimable by utilizing formula (30); the electric field intensity as the limit parameter $E_{\max }$ is set according to Eq. (2) and can be, in the vicinity of an atom of the structure, considered identical for both the radial and the tangential components (2).

To experimentally develop the formation and application technologies suitable for the above-modeled, benzene core-based organic structures, we designed and tested a plasma jet, performing a specific analysis [37] to ensure highly efficient modification of the plasma discharge precursor. In this context, we also investigated diverse methods for optimizing the argon discharge with respect to the frequency required to set the optimal power output transmission (resonance; lossless power output transmission along the path of the plasma discharge). Using the numerical approaches described above, we parametrically investigated the conditions for maintaining the plasma discharge. The discharge very effectively shaped the organic precursors in the frequency band and its multiples (Eqs. 2, 3, Fig. 10). Such modified precursors, when applied to the surface of the material, form the desired "polymeric" nanostructures, with a basic elements of the benzene core type.

We measured the HF parameters along the plasma discharge (Fig. 21a-b) and carried out the relevant basic experiments to ensure the conditions shown in Fig. 21c, d. The indicated setting is expected to facilitate, via the above-presented numerical models, effective formation of organic periodic structures on the desired sample material surface. 

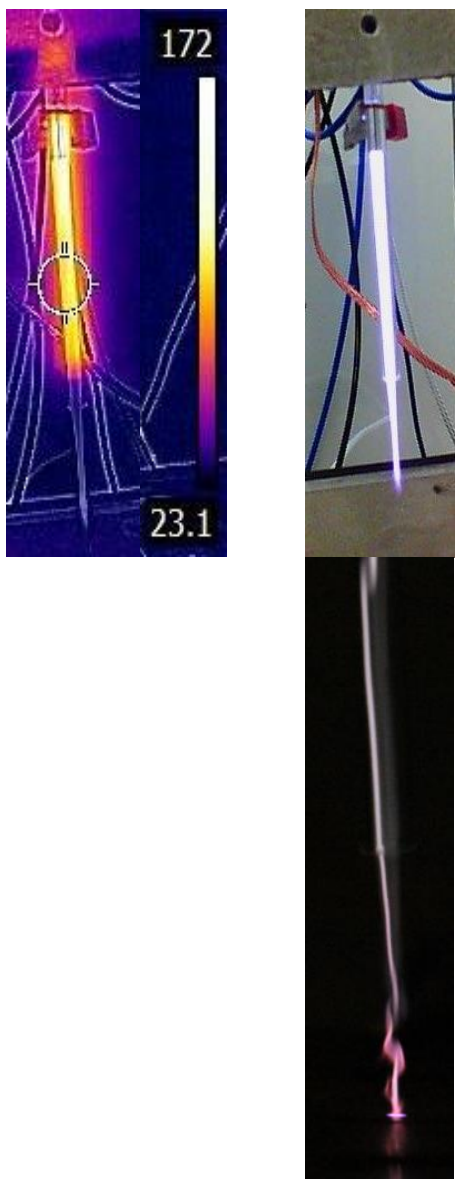

(a)

(b)
Frequency dependence of the $Z_{11}$ module

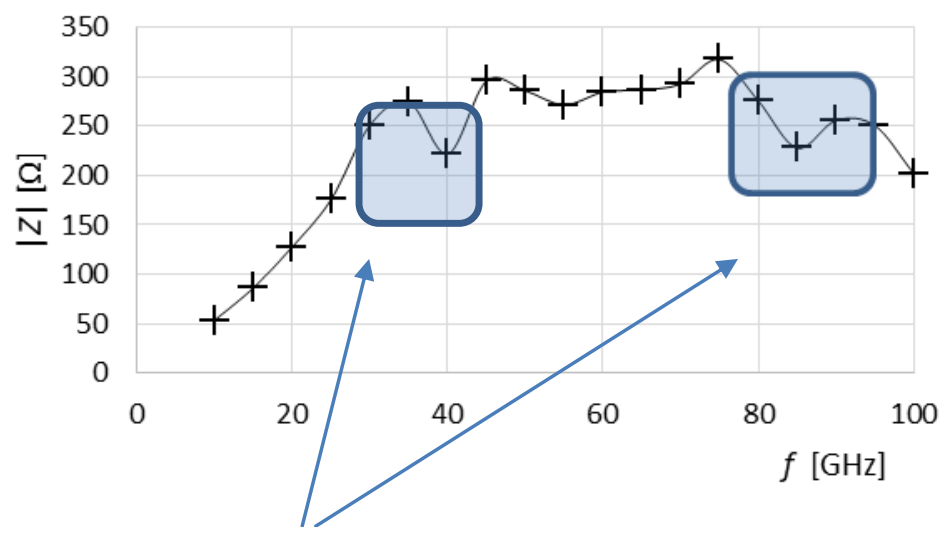

Target area suitable for organic structure modification

Phase of the $Z_{11}$ module

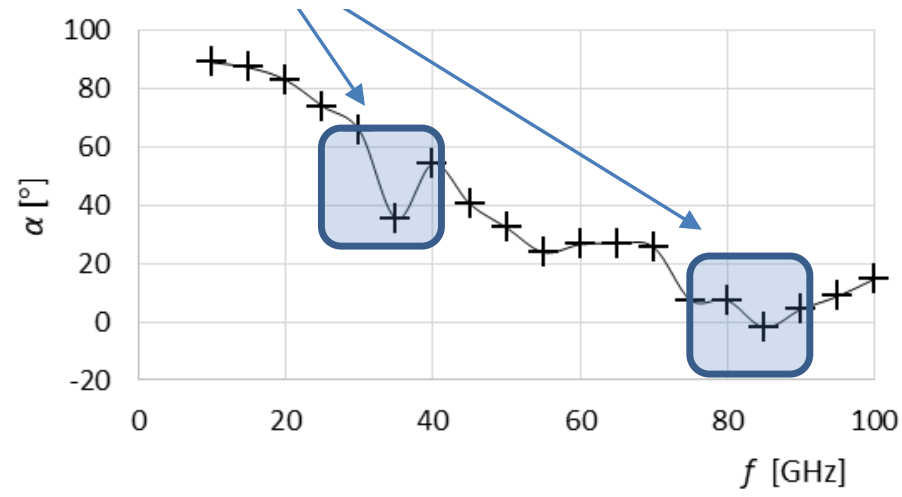

(c)
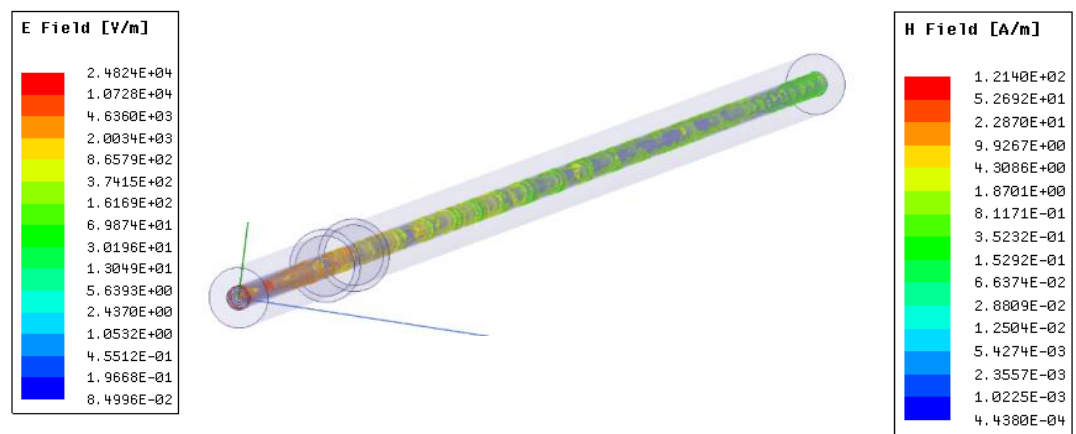

(d)

Fig. 21. Model of the channel plasma jet (EMG generator output $\left.P_{\text {out }}=10 \mathrm{~W}\right):$ a) argon discharge in the IR spectrum; $\left.b\right)$ argon discharge in the visible spectrum; $\left.c\right)$ spectral analysis of the parameter $z_{11} ; d$ ) electric field intensity $E[\mathrm{~V} / \mathrm{m}]$ and magnetic field intensity $\mathrm{H}[\mathrm{A} / \mathrm{m}], f=40 \mathrm{GHz}$

\section{Results of the numerical modeling}

The analyses of the numerical models exploiting the precondition (1) for the frequency region A), Fig. 18a, show that the electric and magnetic components (having the intensities $E$ and $H$, Figs. 18 and 19a) of an electromagnetic wave in close vicinity of the carbon atoms of the modeled periodic systems are distributed unevenly. Such a distribution then implies, in the time domain, a spurious signal added to the transmitted signal of the excitation electromagnetic wave and also degraded $\mathrm{S} / \mathrm{N}$ parameters in the given space of the modeled structure. These effects manifest themselves as additive noise in the transmission of the useful signal, as already determined through similar tasks previously (although with geometries in the order of $\mathrm{mm}$ to $\mathrm{m}),[7,19,20]$.

The evaluated numerical model of the designed coaxial line for the frequency region B, Fig. 5e, displays uneven distribution of the electric and the magnetic fields having electric intensities $E$ and magnetic flux densities $B$, respectively (Fig. 20a, b).
For the purposes of the modeling procedure, we set the following specifications: the anticipated limit values of the current density $J_{\mathrm{s}, \max }$ as the source of a structure's electromagnetic field (31); the limit intensity of the electric field $E_{\mathrm{t}}$ of the designed model of a given structure; and the macroscopic parameter of the electrical conductivity $\gamma$ calculated from the Bohr-Sommerfeld model [36]. These parameters are indispensable for the evaluation of the electromagnetic fields and possible comparison with the experimental measurements centered on the A) and B) frequency domains.

The models calibrated in this manner, for the above conditions (1) ad A) and ad B), allow us to consider the expected results of the analyses, such as that of the DNA [28]; these models can then be formed by using not only implicit approaches and experiments, but also explicit description and evaluation of the electromagnetic field and its quantities. In application terms, nanotechnology may exploit models and analyses published previously, including those comprised in sources $[6,7,10,11,14,17,19,28,33]$ 


\section{Conclusion}

We designed geometrical models of graphene-, graphite-, and graphane-based nanostructures exhibiting high periodicity. In this context, a modeling approach was proposed that simulates the electromagnetic parameters of the selected periodic systems with respect to the frequency bands of the transmitted signals and electromagnetic wave propagation. We then formed a simple model to capture the propagation of an electromagnetic wave and created a hybrid numerical model for solving the simulated structures, whose element dimensions approach the wavelengths of the transmitted signal; the models include the dynamics and effects of the relative motion of parts of the system in relation to one another and an external environment, namely, an electromagnetic field.

From the perspective of numerical model design, we defined the key limit parameters (the current density, electric field intensity, and electrical conductivity) enabling us to identify, during the evaluation of the numerical analyses, the conditions that determine the temporary or permanent character of changes in a designed or fabricated structure.

In accordance with the underlying concept, basic experiments were performed to verify in the structures those properties that accompany the plasma discharge.

The experimental approach to modeling nanostructures centered on signal transmission was presented with respect to the basic parameters required for such an arranged electric line; the described model is narrowly oriented towards this purpose. We outlined the results of the basic experiments with material deposition via plasma technology. In the given context, the proposed procedures and models bring items of knowledge that are seldom discussed in relation to the propagation of EMG waves along periodic (and with not always 100\% periodicity) nanomaterials. Moreover, the presented work opens the path to wholly or partially novel interpretations and options in this subdomain of quantitative structural evaluation; relevant points and activities then include calculating the maximum current load of the nanostructure and a discussion of selecting the numerical analysis technique with respect to the considered frequency spectrum.

Author Contributions: Pavel Fiala and Tibor Bachorec contributed to the theoretical part, numerical modeling, and design of the experiments, and they also co-wrote the paper; Miloslav Steinbauer and Roman Pernica conceived and designed the experiments that allowed partial verification of the effects; and Jiri Zukal with Radim Kadlec modified the manuscript graphically and participated in evaluating the experiments.

Funding: This research was funded by a grant of Czech Science Foundation (GA-20-14105S).

Acknowledgments: The research was funded and supported within a grant of Czech Science Foundation (GA-20-14105S). For the actual analyses and experiments, the infrastructure of the SIX Center was used.

\section{References}

[1] ANSYS, Ansys Multiphysics Manuals, 2020, https://www.ansys.com/

[2] Bartusek K., Drexler P., Fiala P., et al.: Magnetoinductive Lens for Experimental Mid-field MR Tomograph. Progress in Electromagnetics Research Symposium Proceedings 1\&2, 2010, 1047-1050.

[3] Bina M.: The coherent interaction between matter and radiation. The European Physical Journal Special Topics 203(1), 2012, 163-183.

[4] Castro Neto A.H., Guinea F., Novoselov K.S., Geim A.K.: The electronic properties of graphene. Reviews of modern physics 81, 2009, 109.

[5] Chao Yan, Kwang-Seop Kim, Seoung-Ki Lee, Sang-Hoon Bae, Byung Hee Hong, Jae-Hyun Kim, Hak-Joo Lee, Jong-Hyun Ahn: Mechanical and Environmental Stability of Polymer Thin-Film-Coated Graphene. ACS Nano 6(3), 2012, 2096-2103.

[6] Drexler P., Fiala P., Dohnal P., Marcon P.: The Electromagnetic Properties of a Multilayered Resonant Structure Formed from Inorganic Elements. Progress in Electromagnetics Research Symposium 2018, 2176-2183 [https://doi.org/10.23919/PIERS.2018.8597705].

[7] Drexler P., Fiala P., Dohnal P., Marcoň P.: The electromagnetic properties of a resonant structure formed from inorganic or organic elements. Progress in Electromagnetics $\quad$ Research Symposium 2017, 970-974 [https://doi.org/10.1109/PIERS-FALL.2017.8293274].
[8] Drexler P., Nespor D., Kadlec R., Cap M.: Numerical Analysis of Metallic Periodic Structures in $\mathrm{THz}$ Region. Progress in Electromagnetics Research Symposium, 2016, 2730-2733.

[9] Farhana Faisal T., Islam A., Jouini M. S., Devarapalli R. S., Jouiad M., Sassi M.: Numerical prediction of carbonate elastic properties based on multiscale imaging. Geomechanics for Energy and the Environment 20, 2019, 100125 [https://doi.org/10.1016/j.gete.2019.100125].

[10] Fiala P., Bartušek K., Bachorec T., Dohnal P.: An Interference EMG Model of Selected Water Samples. Progress in Electromagnetics Research Symposium 2018, 775-781 [https://doi.org/10.23919/PIERS.2018.8597958].

[11] Fiala P., Bartušek K., Dědková J., Dohnal P.: EMG field analysis in dynamic microscopic/nanoscopic models of matter. Informatyka, Automatyka, Pomiary w Gospodarce i Ochronie Środowiska 9(1), 2019, 4-10.

[12] Fiala P., Drexler P., Nespor D.: A resonance-based solar element: a numerical model and micro/nano technology application. Proc. SPIE 8763, 2013, 87632A1-87632A7.

[13] Fiala P., Drexler P., Nespor D.: Principal tests and verification of a resonancebased solar harvester utilizing micro/nano technology. Microsystem Technologies 20(4-5), 2014, 845-860.

[14] Fiala P., Drexler P.: Power supply sources based on resonant energy harvesting. Microsystem Technologies-Micro-And Nanosystems-Information Storage and Processing Systems 18(7-8), 2012, 1181-1192.

[15] Fiala P., Friedl M.: Application of an electromagnetic numerical model in accurate measurement of high velocities. Informatyka, Automatyka, Pomiary w Gospodarce i Ochronie Środowiska 5(3), 2015, 3-10.

[16] Fiala P., Gescheidtova E., Jirku T.: Tuned Structures for Special THz Applications. Progress in Electromagnetics Research Symposium (PIERS 2009) 2009, 151-155.

[17] Fiala P., Kadlec R., Drexler P.: Modeling multilayered samples of inorganic and organic speckle structures. Progress in Electromagnetics Research Symposium, 2019, 2646-2651 [https://doi.org/10.1109/PIERS-Spring46901.2019.9017266].

[18] Fiala P., Machac J., Polivka J.: Microwave noise field behaves like white light Progress In Electromagnetics Research 111(1), 2011, 311-330.

[19] Fiala P., Maxa J.: Numerical Models of a Multilayered Graphene Structure, Progress in Electromagnetics Research Symposium (PIERS-Toyama) 2018 , 527-532 [https://doi.org/10.23919/PIERS.2018.8598000].

[20] Fiala P., Nespor D., Drexler P., Steinbauer M.: Numerical Model of a Nanoelectric Line from a Graphene Component. Microsystem Technologies 1, 2016, 1-18.

[21] Fiala P., Szabó Z., Friedl M.: EMHD models respecting relativistic processes of trivial geometries. Progress in Electromagnetics Research Symposium, 2011, 95-98.

[22] Fiala P., Werner P., Osmera P., Dohnal P.: Using a multiscale toroidal element to model a hydrogen atom. Progress in Electromagnetics Research Symposium Fall (PIERS - FALL), 2017, 956-960

[23] Fiala P., Werner P., Osmera P., Gescheidtova E., Drexler P., Kriz T.: Periodical structures and multiscale modelling. Progress in Electromagnetics Research Symposium, 2017, 1698-1703.

[24] Geim A.K., Novoselov K.S.: The rise of graphene. Nature Materials 6(3), 2009, 183-91.

[25] Haňka L.: Teorie elektromagnetického pole, paperback SNTL. Praha 1971.

[26] Heyrovska R., Narayan S. Structures of Molecules at the Atomic Level: Caffeine and Related Compounds. Philippine Journal of Science 140(2), 2008, 119-124

[27] Heyrovska R.: Atomic Structures of Graphene, Benzene and Methane with Bond Lengths as Sums of the Single, Double and Resonance Bond Radii of Carbon. General Physics, 2008, arXiv:0804.4086

[28] Heyrovska R.: Methane, benzene and graphene, internal research report. 2008 $\mathrm{http} / / /$ arxiv.org/ftp/arxiv/papers/0804/0804.4086.pdf .

[29] Holmes J., Ishimaru A.: Relativistic communications effects associated with moving space antennas. IEEE Transactions on Antennas and Propagation 17(4), $1969,484-488$.

[30] Hui F., Pan Ch., Shi Y., Ji Y., Grustan-Gutierrez E., Lanza M.: On the use of two dimensional hexagonal boron nitride as dielectric. Microelectronic Engineering 163, 2016, 119-133.

[31] Jović D., Jaćević V., Kuča K., Borišev I., Mrdjanovic J., Petrovic D., Djordjevic A.: The puzzling potential of carbon nanomaterials: General properties, application, and toxicity. Nanomaterials 10(8), 2020, $1-30$ [https://doi.org/10.3390/nano10081508]

[32] Kadlec R., Drexler P.: Analysing the Responses of Layered Materials with Varied Parameters. Progress in Electromagnetics Research Symposium, 2017, 988-992.

[33] Kadlec R., Fiala P.: The Response of Layered Materials to EMG Waves from a Pulse Source. Progress In Electromagnetics Research M 42(1), 2015, 179-187.

[34] Kikuchi H.: Electrohydrodynamics in dusty and dirty plasmas, gravitoelectrodynamics and EHD. Kluwer, Boston 2001.

[35] Kim H.-J., Kang G.-H., Kim S.-H., Park S.: Enhancement of Electromagnetic Wave Shielding Effectiveness of Carbon Fibers via Chemical Composition Transformation Using $\mathrm{H}_{2}$ Plasma Treatment. Nanomaterials 10, 2020, 1611.

[36] Kragh H.: Niels Bohr and the Quantum Atom: The Bohr Model of Atomic

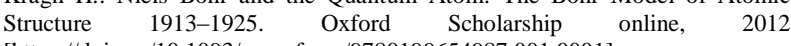
[https://doi.org/10.1093/acprof:oso/9780199654987.001.0001].

[37] Madrova T.: Supravodivost ve čtvrtém skupenství (Superconductivity in the fourth state) - diploma thesis. Brno University of Technology. Brno 2020.

[38] Marinho B., Ghislandi M., Tkalya E., et al.: Electrical conductivity of compacts of graphene, multi-wall carbon nanotubes, carbon black, and graphite powder Powder Technology 221, 2012, 351-358.

[39] Maxwell J. C.: A treatise on electricity and magnetism. London Macmillan and co., Publishers to the University of Oxford, Oxford 1873.

[40] Ozmaian M., Fathizadeh A., Jalalvand M. et al.: Diffusion and self-assembly of C60 molecules on monolayer graphyne sheets. Sci Rep 6, 2016, 21910 , [https://doi.org/10.1038/srep21910]. 
[41] Shin E., Lee B., Jo S., Jeong G.: Investigation of early stage of carbon nanotube growth on plasma-pretreated inconel plates and comparison with other superalloys as substrates. Nanomaterials 10(8), 2020, 1-11 [https://doi.org/10.3390/nano10081595].

[42] Steinbauer M., Fiala P., Szabo Z., Bartusek K.: Experiments with accuracy of the air ion field measurement. Advances in Electrical and Electronic Engineering 8(7), 2008, 276-279.

[43] Stratton J. A.: Electromagnetic Theory. Wiley, New York 1941.

[44] Sun Y., Luo S., Sun H. et. al.: Engineering closed-cell structure in lightweight and flexible carbon foam composite for high-efficient electromagnetic interference shielding. Carbon 136, 2018, 299-308.

[45] Szalay S., Barcza G., Szilvási T., et al.: The correlation theory of the chemical bond. Nature-Scientific Reports 7, 2017, 2237 [https://doi.org/10.1038/s41598017-02447-z]

[46] Urban R., Drexler P., Fiala P., Nespor D.: Numerical Model of a Large Periodic Structure. Proc. PIERS, 2014, 2350-2354.

[47] Van Bladel J.: Motion of a conducting loop in a magnetic field. IEE Proceedings 13.5, Pt. A, no. 4, 1988, 217-222.

\section{Assoc. Prof. Miloslav Steinbauer}

e-mail: steinbau@feec.vutbr.cz

Miloslav Steinbauer has been an associate professor in electrical engineering at Brno University of Technology since 2010. Between 1995 and 2000, he pursued basic research in the simulation of reflections, crosstalk, and distortion on multi-wire lines. Since 2003, he has investigated applications of nuclear magnetic resonance, participated in experiments involving electrical impedance tomography, measured extremely small and extremely fast signals, and designed sensors and methodology to measure parameters of ultrashort electromagnetic pulses with the power of $100 \mathrm{MW}$ and to monitor fast unrepeatable voltage and current waveforms (up to $10 \mathrm{kA}, 100 \mathrm{kV}$ ). Since 2015 , he has also focused on NQR spectroscopy. Miloslav Steinbauer is a regular reviewer of IEEE and PIER \& JEMWA journals

https://orcid.org/0000-0002-1358-6974

\section{M.Sc. Roman Pernica}

e-mail: xperni05@stud.feec.vutbr.cz

Roman Pernica received an M.Sc. in electrical engineering from Brno University of Technology (BUT) in 2001. Since then he has been active in HV device design, delivering models and ensuring their implementation. He is currently working towards a Ph.D. at BUT, investigating the influence of nanosurfaces on the electrical strength and HV properties of material interfaces.

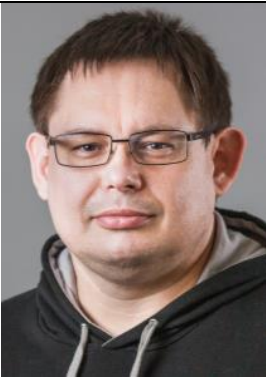

\section{Ph.D. Radim Kadlec}

e-mail: kadlec@feec.vutbr.cz

Radim Kadlec received a Ph.D. degree in electrical engineering from Brno University of Technology (BUT), Brno, the Czech Republic, in 2014. Since 2008, he has been with the Department of Theoretical and Experimental Electrical Engineering, BUT. His research interests are directed towards the analysis and numerical modeling of light conditions at the interface of mediums and also include the modeling of electromagnetic waves. Further, Radim Kadlec focuses on electrical installations, smart homes, and safety in electrical engineering. Since 2015, he has been a member of the research team within the INWITE project, which comprises the research into innovative concepts of wireless communication systems to provide high reliability, speed, and capacity, jointly ensuring widely applicable digital security.

https://orcid.org/0000-0002-3252-4859

Ph.D. Tibor Bachorec

e-mail: bachorec@feec.vutbr.cz

Tibor Bachorec received an M.Sc. (1992) in microelectronics from Brno University of Technology (BUT). From 1989 to 1990, he had studiednumerical methods for physical computations, together with electron and ion optics. In 2006, he obtained a Ph.D. in theoretical electrical engineering. He has engaged in collaborations with industry to execute projects centered on applied numerical modeling, such as the following ones: 2008-2011: Meyer Werft - Jos. L. Meyer GmbH, Papenburg, Germany: Optimization calculations of vessel parts; 2006 CAD-FEM GmbH, Aadorf, Switzerland: Numerical modeling for nuclear power; 2005 CAD-FEM GmbH, Chemnitz, Germany: Numerical modeling of trainsets; 2004 Rücker GmbH, Hamburg, Germany: Numerical modeling for the aerospace industry; 2003 CAD-FEM $\mathrm{GmbH}$, Burgdorf, Germany: Numerical modeling of aircraft elements; 2003 CAD-FEM GmbH, Stuttgart, Germany: Numerical simulations of flow in hydraulic systems; 2001-2002 Meyer Werft-Jos. L. Meyer

$\mathrm{GmbH}$, Papenburg, Germany: Optimization calculations of vessel parts.

https://orcid.org/0000-0002-6249-1509

Prof. Pavel Fiala

e-mail: fialap@feec.vutbr.cz

Pavel Fiala received a Ph.D. in electrical engineering from Brno University of Technology (BUT) in 1998. Since 2014,03, he has been a full professor in theoretical electrical engineering. His professional interests are within modeling and analyzing coupled field problems via numerical methods formulated with partial differential equations by using the finite element, boundary element, and finite difference methods.. Pavel Fiala is a member of the SPIE, APS, OSA, Electromagnetic Academy, Cambridge, USA (since 2007), and a reviewer of the Elsevier, IEEE, and Springer journals.
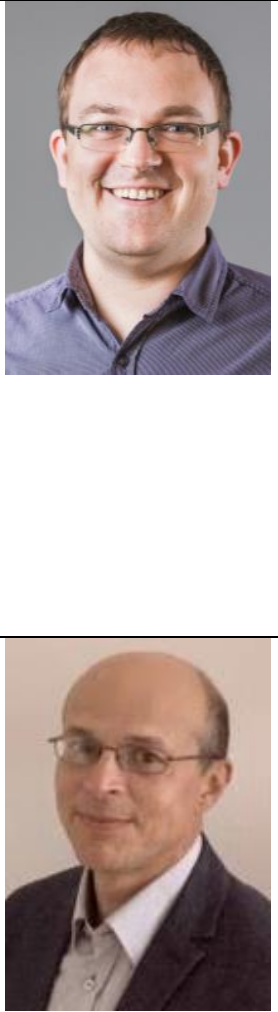